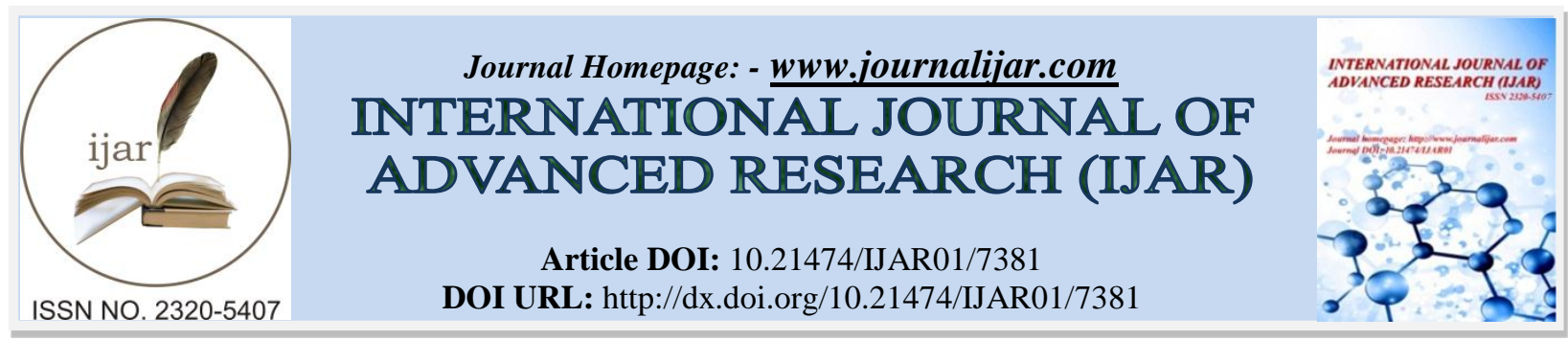

RESEARCH ARTICLE

\title{
MEASURING THE EFFICIENCY OF QUALITY PRODUCT BY USING SIX SIGMA TECHNIQUES.
}

\author{
Dr. Marwan Abdul Hameed Ashour and Abbas Fadhl Kuriea. \\ Statistics department, University of Baghdad, College of Administration \& Economics- Iraq\& Master student \\ Operations Researcher.
}

\section{Manuscript Info}

Manuscript History

Received: 10 May 2018

Final Accepted: 12 June 2018

Published: July 2018

Keywords:-

Quality, Control Schemes, six sigma

Theory, DAMIC Methodology.

\section{Abstract}

Six-sigma theory is one of the most widely accepted theories in the world as a specification seeking to reach customer satisfaction Where the research seeks to apply the theory six sigma in the Baghdad Company for soft drinks through the disclosure of the quality of one of its products And determine the conformity of the product under study to the specifications of the theory, and aims to identify the reservoir of the imbalance in the presence and treatment The Pepsi product was selected as one of the products of the Baghdad Company for soft drinks, where the calculations of the six sigma theory were carried out using the spss program, it was found that the Pepsi product is not conforming to specifications And that its level of quality is the fourth level of the sigma, indicating that there is a defect in its production line Where a thorough examination of the production line by applying the methodology DAMIC of the definition of the problem and measuring the production line and analysis of problems in parts of the line and improve the line and monitor improvements made A defect was detected in one of the parts of the target production line. The defect section was changed for a period of sampling, the results were completed from the experimental period and the theoretical methods were re-applied to the new results after improvement. The results of the analysis confirmed the improvement in quality from level 4 to level 6 , That the most important finding of the research is the non-conformity of the Pepsi product to the specifications of the theory of six sigma and became identical to the level of six Sigma after correcting the defect in the product production line In addition to several recommendations, the most important of which is the application of the theory of six sigma in the company because of the great importance in reaching the satisfaction of consumers, which is aimed at the international companies and replace the section of the defect in the product line Pepsi for the purpose of improving the level of the product and make it within the level of the sixth theory .

Copy Right, IJAR, 2018,. All rights reserved.

\section{Introduction:-}

Companies and productive institutions seek to reach the highest levels of quality for their satisfaction In the light of the development and modern technologies, companies are working to study the quality and the most important

Corresponding Author:-Marwan Abdul Hameed Ashour. 
factors of success and reduce the defects and maintenance of problems incurred for the purpose of reducing costs and be achieved to achieve the wishes of the customer Six-Sigma theory has been used, which is the highest level of quality as a global standard after this theory has achieved a reduction in the percentage of defects and improvement of the product, through which it is possible to know the level of the company's work and to improve its quality level $\mathrm{t}$ has proven its application in many international companies such as General Electrotech, Motorola, Sony, etc. The importance of sikma in improving quality and reducing cost by adopting the principle of near perfection which seeks to reduce the defects to (3.4) defects per million units and thus reduce the cost, Through a set of tools used to achieve it.

The problem of research is not to adopt international quantitative standards to measure the quality of the products of the Baghdad Company for soft drinks, which contributes to the attention of senior management to the importance of this theory and its role in measuring the quality of the product and identify the imbalance and reduce costs.

The aim of the research is to implement the methodology of the Six Sigma theory at the Baghdad Company for soft drinks by detecting the level of quality of one of the company's products. It also aims to diagnose and treat the defect to ensure that the product follows the Six Sigma methodology and work according to international standards.

The fourth part discusses the methodology of the research in the first subject. In the second part, we discuss the theoretical aspect according to the reliable sources, while the third section deals with analyzing the data and interpreting the results. The fourth discusses the conclusions and recommendations.

Research related to the subject matter may be directed to:

To compare organizations using only Sigma and organizations that use an integrated approach by exploring research questions to what extent organizations that apply an integrated method to improve quality differ in the success and duration of their Sigma programs compared to those that implement the DHT as a separate method. Factors contributing to the successful integration of the six-sigma and system thinking, as well as the differences in driving support for an integrated model compared to those that use only Sigma (Derian, 2013)

Explain the application of the six sigma theory in the companies to produce the purpose of improving the quality of pharmaceuticals and the requirements of successful application and the difficulties facing the application, where several requirements were reached in three main categories (administrative, technical and human requirements that must be available) Must be provided together to create the appropriate environment for the implementation of the theory of diffraction of the six successfully, has been possible through the application of the six sigma theory of in the Syrian pharmaceutical company to make significant improvements in their products in parallel with increasing their ability to adhere to and meet the requirements of customers with possible Reduce costs. (Basel, 2014)

The application of the six sigma theory in one of the Jordanian industrial companies where the role of the theory was explained in reducing the proportion of defects and maximize profits, and highlight the possibility of applying the methodology of this method and to what extent the impact of standards in reducing costs, and the most important results are that the company content research does not apply The method of six sigma is not available and the possibility of applying the requirements of the curriculum and in the case of the company's application of the curriculum will lead to reduced costs and increase the production and increase the efficiency of quality. (Hussein, 2014)

The Baritwa scheme was adopted to find the difference between the six sigma theory and hexagonal diffraction theory in terms of application as well as to identify the main and secondary reasons that led to the reluctance of customers about the products of the company. (Dawood and Karim, 2016)

Using the linear programming methodology to improve and monitor the stages of the Six Sigma project to find the truck scheduling tool for APC Transport to reduce their shipping costs and then identify the main cost variables and probability distributions at the analysis stage. Significantly. (Yanhui, David, \& J., 2016)

The application of the six-sigma theory in an industrial company, referred to as six sigma DMAIC Enhanced Schema with a capacity modeling approach through which the requirements can be considered operationally and strategically. The main objective of this approach is to use a set of modeling techniques in a systematic manner under a comprehensive and well-established approach of process management To enable key stakeholders to 
consider needs to improve existing problems and exploit new business opportunities and manage the shift from traditional operations towards CPS. (Mathran, 2017)

\section{Theoretical side:-}

Quality Concept:-

Companies and production and service organizations seek to achieve a high level of quality produced or offered because they have a significant impact in maintaining competitive advantage on the local or global side, improving the reputation of the institution or the company and increasing its market share in the case of productivity and thus increase profitability. (Ali, 2010)

\section{Quality control:-}

That each of the supervision, regulation and guidance and adjustment operations for the purpose of ascertaining the conformity of the product specific specifications or specific conditions and make corrections by, and the international organization known for Standardization and Quality Control "as a set of operations of programming and coordination and implementation, which aims to enhance or improve the quality and make the product less Cost so that consumer satisfaction ". (Ahmed, 2010)

The second definition of quality control consists of the regular procedures in which the establishment acts as a measure of the actual quality of the product's performance, its conformity with the specific specifications and corrective measures that may be taken in the event of any deviation in the specifications. The third definition is the processes of planning and coordinating efforts to control and improve the quality of the product from Before the establishment branches or the production company for the purpose of meeting consumer requirements at the lowest possible cost.

$\mathrm{n}$ the opinion of the quality control are: tools to evaluate and develop the product for the purpose of reaching a level of quality that meets the wishes of the customer and increases the profits of the company while working to reduce costs to reduce damaged products.

\section{Types of Quality Control:-}

Quality control depends on three types: (Abdel-Al, Jalil, and Jalil, 2009)

1. Quality control of the front: They match the materials involved in the production process of the required conditions.

2. Current quality control: the production of the production line under observation, especially when moving from one stage to the second phase of the production line, which is important because the cost of imbalance in the production line is very large.

3. Quality control: After the production process of the products checked to meet the specifications required and in the case of defects are repaired or excluded.

\section{Control Schemes:-}

The control master plans are the main determinant in the process of quality of the production process. Therefore, it has received wide attention by researchers and specialists in this field as well as focused on many companies and productive institutions. In this section we highlight their basic concepts and details.

\section{Concept control maps:-}

Monitoring maps are one of the most important centers of statistical control of operations, through which continuous statistical analysis of any change in the production process is carried out in order to control the characteristics of the products or services (product or service) and improve the performance of the process. The process of making the right decision to get to the best performance of the production process Control maps are made up of a diagram showing the changes that occur in the components and characteristics of the product over time,

Where it is possible to distinguish between natural changes, which consist of the general reasons inherent in the process and the changes that result from specific causes, are drawn on two axes: the $\mathrm{x}$ axis, where the time or the sampling number and the $y$ axis are the statistical indicator of quality, Through which the mean range, mean value, or standard deviation in the sample 
In addition to this, three horizontal lines are added to the control plan, each representing a certain point where the center line or center line (CL) can be achieved in the property, upper control limit (UCL) and minimum control Control Limit-LCL) represents the maximum that can be accepted in the property changes studied when the process is in the statistical control mode. The sampling process (production units) should not exceed the effects of natural changes.

\section{Range control maps:-}

The control maps for the ranges are the most important control maps on which many productive industrial companies and service institutions depend. They allow measuring the degree of dispersion in the product under study. If $\mathrm{X} 1, \mathrm{X} 2, \mathrm{X} 3, \ldots . . \mathrm{Xn}$ is a sample of size $\mathrm{n}$, The sample range is the difference between the highest value and the smallest value of the observations as shown in the following equation: (Montgomery, 2009)

$\mathrm{R}=\mathrm{X}_{\text {Max }}-\mathrm{X}_{\text {Min }} \ldots \ldots \ldots$ (1)

On the assumption that $\mathrm{R} 1, \mathrm{R} 2, \mathrm{R} 3, \ldots \ldots . . \mathrm{Rm}$ are dimensions of size $\mathrm{m}$, the rate of ranges can be calculated by the following equation:

$\overline{\mathrm{R}}=\frac{\mathrm{R}_{1}+\mathrm{R}_{2}+\cdots+\mathrm{R}_{m}}{m}$

The change in the production process of the sample drawn for the test can be monitored using the control schemes for ranges, which can be written in the following equations:

$$
\begin{aligned}
& \text { (3) } \ldots \ldots \ldots \ldots \quad \mathrm{UCL}=\mathrm{D}_{4} * \overline{\mathrm{R}} \\
& \text { ) ..... }(4 \quad \overline{\mathrm{R}} \mathrm{CL}= \\
& \text { ) } \ldots . .\left(5 \mathrm{UCL}=\mathrm{D}_{3} * \overline{\mathrm{R}}\right.
\end{aligned}
$$

Where D3, D4 are constant values

The control scheme for the ranges can be represented as in Figure (2-2) where it is noted how the data is defined by the points and the exit of some values outside the upper limit so the production line should be reviewed and the problem addressed

Of processors:

1. Treatment of sample repair: maintenance of defect in the production line and maintenance of the withdrawn sample

2. Replace the sample: ie maintenance of faults in the production line and replacement of the withdrawn sample (sample damage).

In the case of values within the limits indicates the stability of the production process, that is, the process is statistically controlled. (Montgomery, 2009)

Control maps for the average:-

The control maps of the averages depend on monitoring the changes in the mean value and on finding the mean for the data and then calculating the upper, minimum and mean values as shown in the following equations: (Montgomery, 2009)

$\bar{X}=\frac{\sum_{i=1}^{m} X i}{m} \ldots .(6)$

Where $\bar{X}$ represents the arithmetic mean of views

$$
\begin{array}{r}
\mathrm{UCL}=\overline{\bar{X}}+A 2 * \bar{R} \\
\quad \ldots .(8 \mathrm{CL}=\overline{\bar{X}} \\
) \ldots\left(\begin{array}{r}
9 \mathrm{LCL}=\overline{\bar{X}}-A 2 * \bar{R}
\end{array}\right.
\end{array}
$$

$\overline{\bar{X}}$ represents the arithmetic average of observations

And $\bar{R}$ يمثل represents the average range of observations under study

Where $\mathrm{A}_{2}$ is a constant value

\section{Concept of the Six Sigma theory:-}

The six sigma theory is a measure of quality that works to reach the defect in the final product to 3.4 million units, or $99.997 \%$ of the defects or errors in the output of the process.

\section{DMAIC Sample:-}

(Define, Measure, Analysis, Improve, Control), which is a map of the work of the six-party diffraction, which depends on the control of the production process. The words can be defined as follows: (Park, 2003) 


\section{Define:-}

Which is a statement of the current situation and diagnosis of the process and at this stage is agreed between the team and sponsors on what the project includes the following:

1. Where the problem occurs and the process name

2. Availability of customer data

3. The size of the problem

Thus creating a clear picture of the problem under study

\section{Measure:-}

At this stage, using statistical methods such as the central quality standards and measurements of dispersion and probability distributions for the purpose of analysis.

\section{Analysis:-}

Upon reaching the analysis stage, the data obtained from the previous stage will begin to be used for the purpose of identifying the faults that cause the problems and to develop the specific hypotheses about the real causes of the problem and using several methods of analysis (Pareto analysis, cause and effect analysis, multivariate analysis)

\section{Improve:-}

At this stage, the problem is addressed and the means of developing the performance in order to reach the specifications required to achieve customer satisfaction or achieve the highest level of performance, where a collection of the main ideas of the problem as they begin testing the proposals formulated and implemented

\section{Control:-}

When this stage is reached, it is necessary to ensure that the course of modifications continues over time and not to repeat errors and not to refer to the random methods that led to the error and include the following control phase (control maps, post-roll maps)

\section{Methods of diffraction theory:-}

The six-sigma model is based on a number of mathematical laws and methods. The deviation of the values is derived from the arithmetic mean or the value of acceptance of the company, as follows:

\section{Ability to process production:-}

$$
\ldots(10)=\frac{\bar{R}}{d_{2}} \bar{\sigma}
$$

Where $\bar{\sigma}$ represents the production capacity

And $\bar{R}$ يمثل represents the average viewing range

And $\mathrm{d}_{2}$ represents a constant value

Process capability indice:-

Power indicators are simplified which briefly describe the relationship between the volatility of the process and its dispersion from the specification limits. There are several types of indicators of production that can be explained by the following points:

2-12-1 Production Capability Index $\mathrm{Cp}$ :

(UCL, LCL) on the dispersion of the process, which can be represented by six deviations, as shown in the following equation: (Kai and EL-Haik, 2003)

.... ( 11$) \mathrm{Cp}=\frac{\mathrm{UCL}-\mathrm{LCL}}{6 \sigma}$

Where Cp represents an estimated index

And that UCL represents the upper limit of acceptable value

The LCL represents the minimum limit of acceptable value

$\mathrm{Cp}$ assumes that normal distribution is the correct model of the process, which means that the indicator does not take into account the concentration of the process and its average impact, causing errors in the case of distribution deviation from normal distribution, in addition to the possibility of translating $\mathrm{Cp}$ directly to the percentage or proportion of products out of conformity The following points can be noted:

1. The process is not able to meet the specifications in the case of $\mathrm{Cp}<1$ and must find solutions to the problems of the production line.

2. The process is also of moderate capacity and should be sought to improve in the case of $1<\mathrm{Cp}<1.6$. 
3. In addition to the process is considered to be of good ability and meet the specifications required in the case of $\mathrm{Cp}>1$.

\section{Resource indicators based on specification limits Cpk:-}

As indicated in the Cp production index, it is not associated with the average operation and achieving its objective, which may lead to large errors, which led the researchers to use the Cpk production capability indicator to avoid defects of the previous production capability index.

Where the index of production capacity based on the specifications of each limit of the specifications of one or both of them and the dispersion of the process and the average and as shown in the following equations: (Kai and ELHaik, 2003)

$$
\text { ......(12) } \mathrm{Cpu}=\frac{U C L-m}{3 \sigma}
$$

Where Cpu represents a production capacity indicator of the upper limit

UCL has the highest specification

And that $m$ is the average process

And that $\sigma$ the ability of the process

$$
\text { (13) } \mathrm{Cpl}=\frac{m-L C L}{3 \sigma}
$$

Where $\mathrm{CpL}$ represents a minimum production capacity indicator

UCL has the highest specification

And that $\mathrm{m}$ is the average process

And that $\sigma$ the ability of the process

$$
\text { .....(14) }\} \quad \frac{m-L C L}{3 \sigma} \text { and } \quad \mathrm{Cpk}=\min \left\{\frac{U C L-m}{3 \sigma}\right.
$$

Where Cpk represents the production capacity indicator of the specification limits.

\section{Taguchi Cpm:-}

In the late 1980s, the world of Taguchi proposed the development of the former production index, where the world linked the UCL, the process dispersion $(6 \sigma)$, the average operation $(\mathrm{m})$ and the objective of the process $(\mathrm{T})$ ( Aeshuna, 2007)

$$
\text { .....(15) } \quad \mathrm{Cpm}=\frac{U C L-L C L}{6 \sqrt{\sigma^{2+(m-T)^{2}}}}
$$

Where Cpm is the index of Tajoshi production capacity

UCL has the highest specification

Wan LCL has a minimum specification

And that $m$ is the average process

And that $\sigma$ the ability of the process

$\mathrm{T}$ is the objective of the process

The six-sigma theory is divided into six sections according to international standards, as explained below:

Table 2-1:-Comparison Table ${ }^{1}$ (Park, 2003)

\begin{tabular}{|l|l|l|}
\hline Number of defects & The level of six sigma theory & Estimated Index \\
\hline 697,672 & 6 & 0.50 \\
\hline 308,770 & $\mathbf{6 ~ 2}$ & 0.67 \\
\hline 66,811 & $\mathbf{6 ~ 3}$ & 1.00 \\
\hline 6,210 & $\mathbf{6 ~ 4}$ & 1.33 \\
\hline 233 & $\mathbf{6 ~ 5}$ & 1.67 \\
\hline 3.4 & $\mathbf{6 ~ 6}$ & 2.00 \\
\hline
\end{tabular}

\footnotetext{
${ }^{1}$ Table of work of the researcher
} 
The table shows the six levels of the six igma theory, as well as the production estimator index, by which the quality of the company is compared with the corresponding level of theory. The table shows the number of defects corresponding to each level. The theory starts with $(697,672)$ million products at the first level, which is the number of the production process, Then the number starts to decline until reaching the sixth level, where the number of defects (3.4) million products is a very acceptable number and is ideal for quality, which seeks to achieve the decision makers of enterprises and production and service companies.

\section{Repeated readings:-}

Repeated readings consist of several readings that may be 2 or more for each of the studied observations and for each sample of the studied products. The measurements use the center's tendency to solve the problems of repeated readings.

\section{Treatment:-}

Centralized measure of the most important methods of processing of repeated readings, which works to represent the data under study with a single value centered in the center, working at the expense of the values that are centered around most of these data and is represented by one number that reflects or represents all the product data teacher, Central:

1. The mean

2. The engineering center

3. The Harmonic Center

4. The Quadratic center

5. The mode

6. The median

The intermediary has been adopted as being the most common and used in various fields, industrial or service.

\section{Median:-}

The median is also one of the measures of central tendency and defined as the value for which a given group is mediated ascending or descending order so that the number of values on both ends of the median is equal. The mediator is not affected by extreme or small extreme values. It can also be used with descriptive data. Values can be calculated using the following formula: (Narrator, 1989)

$$
\text { .....( } 17 \text { ) } \mathrm{M}_{\mathrm{o}}=\frac{n+1}{2}
$$

Where Mo represents the mediator

And $\mathrm{n}$ represents the number of variable values

\section{The practical side:- \\ Data collection:-}

Data were collected from the Baghdad Company for Gas Turbines through the quality control department of the company. The department is responsible for classifying and classifying the data of samples extracted from the production lines on a daily basis, with one withdrawal at each inspection, The samples were studied in 500 samples for each of the company's products (the producer of the 7up , the producer of the marinda, the Pepsi product). Products on the basis of the high demand by consumers and being in direct contact with the satisfaction of the customer and the desire to buy them and the opinion of experts and stakeholders in the company, The sample consists of 50 productive days and each day 10 observations. Each display consists of three readings. There are three measurement measures approved by the company. These are the limits of control set by the standardization, control, quality and control limits set by the parent company and the limits of control by the company Baghdad and took the eyes for each day at close intervals and is shown in the annexes $(1,2,3)$. The production period of the ship product has been studied from 10/2/2016 to 1/12/2017. 2016 to 29/12/2016 and the Pepsi product from 26/10/2016 to $22 / 2 / 2017$, ote that the company is in the process of testing almost every text hour procedure during the day productive, where the work Alhevcat system at a rate of two lips per day (morning and evening) and the screening process begins at 7:30 am and the first screening process will be 40 minutes after the rest of the times of examination are every half hour at a rate tray for each scan. 


\section{Data Processing:-}

That the company's product data are repeated readings because there are three parameters of the control limits represented by the limits of the control of the center control of the quality control and control limits of the parent company and the limits of the control of the Baghdad Company for soft drinks, including three readings for each view of the views drawn in the research sample where the first reading is approved On the limits set by Baghdad Company and the second reading is based on the limits specified by the parent company The third reading in the approved limits of the control of the standardization and quality control, We work on the processing of these three readings through the use of the medium by applying equation (17), which works at the average value of the view by the Excel program, where the Pepsi product is produced almost daily and throughout the year, the limits of the adjustment of the Pepsi of three limits, $(3.45,3.60,3.75)$. The limits of the device settings are from the minimum, the middle and the highest $(3.4,3.6,3.8)$ respectively, and the limits of the company's settings $(3.3,3.6,3.7)$ As in the table below:

Table 3-1:-Treatment evidence for the Pepsi product

\begin{tabular}{|c|c|c|c|c|c|c|c|c|c|c|c|}
\hline $\mathrm{x10}$ & x9 & $\mathrm{x} 8$ & $\mathrm{x} 7$ & $\mathrm{x6}$ & $\mathrm{x} 5$ & $\mathrm{x4}$ & $\mathrm{x} 3$ & $\mathrm{x} 2$ & $\mathrm{x1}$ & Date & $\mathbf{n}$ \\
\hline 3.57 & 3.61 & 3.59 & 3.57 & 3.61 & 3.66 & 3.67 & 3.61 & 3.59 & 3.59 & $26 / 10 / 2016$ & 1 \\
\hline 3.67 & 3.62 & 3.55 & 3.57 & 3.61 & 3.58 & 3.60 & 3.63 & 3.62 & 3.61 & $27 / 10 / 2016$ & 2 \\
\hline 3.62 & 3.52 & 3.69 & 3.59 & 3.57 & 3.55 & 3.61 & 3.69 & 3.61 & 3.59 & $29 / 10 / 2016$ & 3 \\
\hline 3.60 & 3.69 & 3.69 & 3.65 & 3.58 & 3.59 & 3.57 & 3.61 & 3.66 & 3.59 & $30 / 10 / 2016$ & 4 \\
\hline 3.59 & 3.57 & 3.69 & 3.63 & 3.59 & 3.57 & 3.67 & 3.69 & 3.61 & 3.59 & $31 / 10 / 2016$ & 5 \\
\hline 3.62 & 3.69 & 3.57 & 3.69 & 3.65 & 3.67 & 3.62 & 3.69 & 3.61 & 3.59 & $01 / 11 / 2016$ & 6 \\
\hline 3.69 & 3.66 & 3.61 & 3.57 & 3.64 & 3.59 & 3.57 & 3.61 & 3.66 & 3.59 & $02 / 11 / 2016$ & 7 \\
\hline 3.59 & 3.57 & 3.69 & 3.62 & 3.54 & 3.58 & 3.57 & 3.69 & 3.61 & 3.59 & $03 / 11 / 2016$ & 8 \\
\hline 3.69 & 3.64 & 3.57 & 3.59 & 3.59 & 3.57 & 3.62 & 3.69 & 3.67 & 3.59 & $06 / 11 / 2016$ & 9 \\
\hline 3.59 & 3.57 & 3.59 & 3.69 & 3.62 & 3.59 & 3.57 & 3.69 & 3.61 & 3.59 & $07 / 11 / 2016$ & 10 \\
\hline 3.69 & 3.52 & 3.59 & 3.57 & 3.69 & 3.60 & 3.59 & 3.57 & 3.61 & 3.59 & $08 / 11 / 2016$ & 11 \\
\hline 3.68 & 3.65 & 3.57 & 3.59 & 3.69 & 3.57 & 3.58 & 3.61 & 3.54 & 3.59 & $09 / 11 / 2016$ & 12 \\
\hline 3.60 & 3.62 & 3.64 & 3.62 & 3.58 & 3.60 & 3.61 & 3.57 & 3.60 & 3.62 & $10 / 11 / 2016$ & 13 \\
\hline 3.62 & 3.68 & 3.59 & 3.57 & 3.61 & 3.62 & 3.68 & 3.69 & 3.61 & 3.61 & $14 / 11 / 2016$ & 14 \\
\hline 3.53 & 3.69 & 3.52 & 3.57 & 3.69 & 3.68 & 3.59 & 3.57 & 3.51 & 3.59 & $15 / 11 / 2016$ & 15 \\
\hline 3.57 & 3.69 & 3.59 & 3.55 & 3.62 & 3.52 & 3.57 & 3.59 & 3.64 & 3.59 & $23 / 11 / 2016$ & 16 \\
\hline 3.62 & 3.57 & 3.64 & 3.69 & 3.57 & 3.59 & 3.68 & 3.51 & 3.59 & 3.59 & $24 / 11 / 2016$ & 17 \\
\hline 3.69 & 3.52 & 3.62 & 3.57 & 3.69 & 3.59 & 3.61 & 3.57 & 3.61 & 3.59 & $27 / 11 / 2016$ & 18 \\
\hline 3.66 & 3.51 & 3.69 & 3.67 & 3.57 & 3.58 & 3.69 & 3.57 & 3.61 & 3.59 & $28 / 11 / 2016$ & 19 \\
\hline 3.61 & 3.59 & 3.59 & 3.57 & 3.62 & 3.59 & 3.57 & 3.68 & 3.61 & 3.59 & $29 / 11 / 2016$ & 20 \\
\hline 3.59 & 3.55 & 3.57 & 3.61 & 3.54 & 3.68 & 3.62 & 3.69 & 3.60 & 3.59 & $30 / 11 / 2016$ & 21 \\
\hline 3.62 & 3.59 & 3.54 & 3.64 & 3.68 & 3.52 & 3.59 & 3.57 & 3.61 & 3.59 & $01 / 12 / 2016$ & 22 \\
\hline 3.61 & 3.62 & 3.69 & 3.57 & 3.68 & 3.62 & 3.60 & 3.57 & 3.69 & 3.59 & $04 / 12 / 2016$ & 23 \\
\hline 3.62 & 3.59 & 3.60 & 3.56 & 3.57 & 3.59 & 3.69 & 3.58 & 3.52 & 3.59 & $05 / 12 / 2016$ & 24 \\
\hline 3.59 & 3.57 & 3.62 & 3.52 & 3.59 & 3.57 & 3.69 & 3.61 & 3.57 & 3.59 & $06 / 12 / 2016$ & 25 \\
\hline 3.59 & 3.57 & 3.68 & 3.51 & 3.69 & 3.57 & 3.62 & 3.69 & 3.61 & 3.59 & $07 / 12 / 2016$ & 26 \\
\hline 3.65 & 3.64 & 3.61 & 3.62 & 3.59 & 3.57 & 3.60 & 3.58 & 3.61 & 3.62 & $08 / 12 / 2016$ & 27 \\
\hline 3.60 & 3.66 & 3.55 & 3.57 & 3.64 & 3.59 & 3.57 & 3.61 & 3.59 & 3.59 & $12 / 12 / 2016$ & 28 \\
\hline 3.69 & 3.52 & 3.59 & 3.67 & 3.69 & 3.62 & 3.52 & 3.69 & 3.51 & 3.59 & $13 / 12 / 2016$ & 29 \\
\hline 3.57 & 3.59 & 3.59 & 3.69 & 3.52 & 3.54 & 3.62 & 3.69 & 3.61 & 3.59 & $14 / 12 / 2016$ & 30 \\
\hline 3.58 & 3.57 & 3.69 & 3.52 & 3.58 & 3.57 & 3.60 & 3.57 & 3.61 & 3.55 & $17 / 01 / 2017$ & 31 \\
\hline 3.52 & 3.57 & 3.69 & 3.65 & 3.57 & 3.55 & 3.61 & 3.59 & 3.57 & 3.59 & $18 / 01 / 2017$ & 32 \\
\hline 3.55 & 3.65 & 3.55 & 3.64 & 3.55 & 3.60 & 3.58 & 3.65 & 3.65 & 3.55 & $19 / 01 / 2017$ & 33 \\
\hline 3.52 & 3.57 & 3.61 & 3.69 & 3.57 & 3.61 & 3.61 & 3.59 & 3.57 & 3.55 & $22 / 01 / 2017$ & 34 \\
\hline 3.69 & 3.57 & 3.64 & 3.58 & 3.59 & 3.60 & 3.61 & 3.57 & 3.66 & 3.52 & $23 / 01 / 2017$ & 35 \\
\hline 3.59 & 3.67 & 3.57 & 3.58 & 3.69 & 3.52 & 3.67 & 3.67 & 3.54 & 3.57 & $24 / 01 / 2017$ & 36 \\
\hline 3.60 & 3.61 & 3.59 & 3.64 & 3.58 & 3.62 & 3.57 & 3.69 & 3.61 & 3.59 & $26 / 01 / 2017$ & 37 \\
\hline 3.62 & 3.59 & 3.57 & 3.59 & 3.62 & 3.57 & 3.69 & 3.57 & 3.67 & 3.57 & $29 / 01 / 2017$ & 38 \\
\hline 3.39 & 3.57 & 3.55 & 3.60 & 3.67 & 3.50 & 3.61 & 3.60 & 3.69 & 3.61 & $30 / 01 / 2017$ & 39 \\
\hline
\end{tabular}




\begin{tabular}{|l|l|l|l|l|l|l|l|l|l|l|l|}
\hline 3.69 & 3.52 & 3.50 & 3.39 & 3.61 & 3.69 & 3.59 & 3.57 & 3.67 & 3.61 & $31 / 01 / 2017$ & 40 \\
\hline 3.57 & 3.60 & 3.57 & 3.58 & 3.54 & 3.64 & 3.52 & 3.51 & 3.59 & 3.59 & $01 / 02 / 2017$ & 41 \\
\hline 3.57 & 3.69 & 3.57 & 3.69 & 3.57 & 3.64 & 3.57 & 3.56 & 3.55 & 3.67 & $02 / 02 / 2017$ & 42 \\
\hline 3.57 & 3.64 & 3.69 & 3.57 & 3.61 & 3.59 & 3.57 & 3.68 & 3.61 & 3.59 & $12 / 02 / 2017$ & 43 \\
\hline 3.69 & 3.57 & 3.59 & 3.57 & 3.59 & 3.62 & 3.68 & 3.69 & 3.57 & 3.61 & $13 / 02 / 2017$ & 44 \\
\hline 3.69 & 3.54 & 3.69 & 3.62 & 3.58 & 3.62 & 3.54 & 3.69 & 3.57 & 3.59 & $14 / 02 / 2017$ & 45 \\
\hline 3.56 & 3.65 & 3.68 & 3.61 & 3.57 & 3.52 & 3.69 & 3.68 & 3.64 & 3.57 & $15 / 02 / 2017$ & 46 \\
\hline 3.52 & 3.62 & 3.69 & 3.67 & 3.67 & 3.57 & 3.55 & 3.59 & 3.64 & 3.57 & $19 / 02 / 2017$ & 47 \\
\hline 3.62 & 3.58 & 3.54 & 3.61 & 3.59 & 3.67 & 3.68 & 3.69 & 3.61 & 3.59 & $20 / 02 / 2017$ & 48 \\
\hline 3.68 & 3.59 & 3.64 & 3.69 & 3.57 & 3.69 & 3.65 & 3.57 & 3.64 & 3.59 & $21 / 02 / 2017$ & 49 \\
\hline 3.61 & 3.63 & 3.64 & 3.57 & 3.69 & 3.57 & 3.62 & 3.69 & 3.64 & 3.61 & $22 / 02 / 2017$ & 50 \\
\hline
\end{tabular}

Calculation of control maps and production indicators:-

Based on equations $(7,8,9)$, control schemes were calculated for the mean, range and calculation of the production indicators of the company's product. Equations $(9,8,7)$ respectively were applied for the extraction of the limits and center of the average control, $(5,4,3)$ and extracting the value of the CP production by using equation (11) and extracting the production capacity based on the specification limits using the equations $(14,13,12)$ and extracting the value of the Taguchi production index by using equation (15), The results are then compared with the table (2-1) of the theory to determine the level of quality of the Pepsi product according to the specification of the six-seismic theory. The results of the analysis of the products under study are shown in Table (2) using the spss program:

\section{Control plan for the average:-}

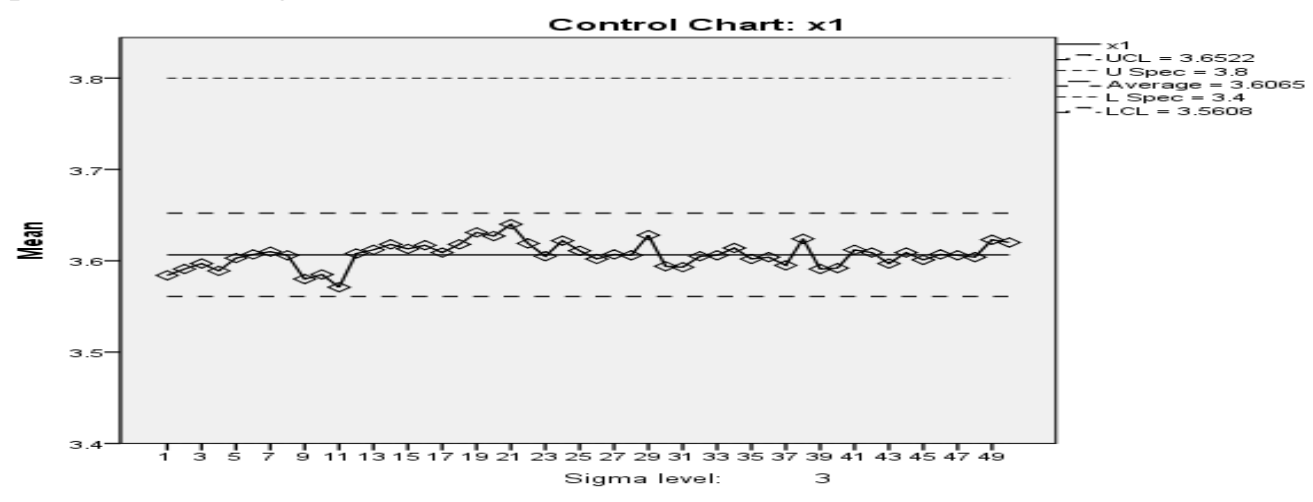

Figure 3-1:-Control plan for the average Pepsi product

he upper limit is calculated by UCL (3.8), the minimum calculated LCL (3.56), the minimum determined by the company (3.40), or the median value (3.60). The production process is within limits and there are no values beyond control, which confirms the progress of the production process on a regular basis, ie scientific within the statistical control.

\section{Range control scheme:-}

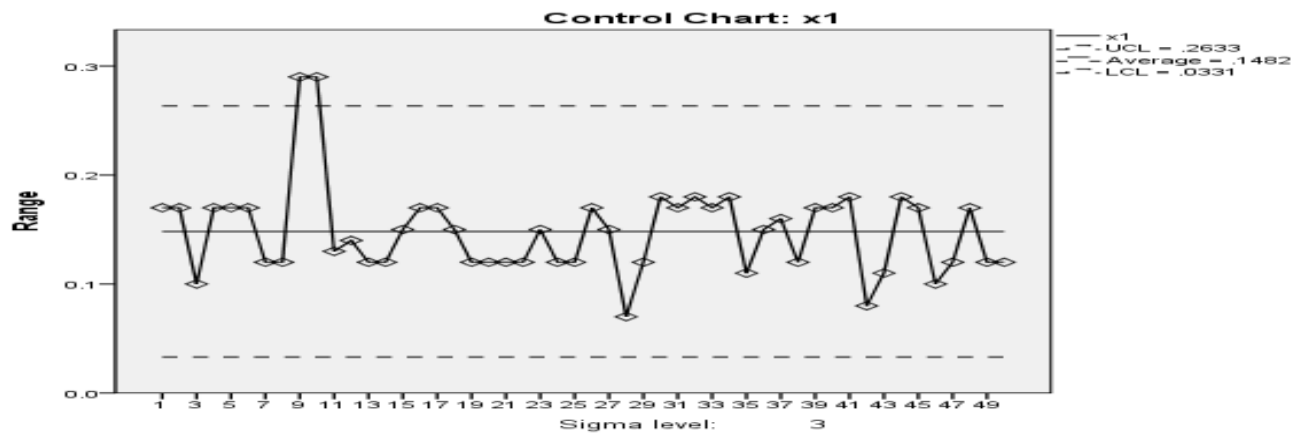

Figure 3-2:-The length control plan for the Pepsi product 
Where the results of the analysis showed that the upper limit UCL $(0.26)$ and the minimum LCL (0.03) and the mean value CL $(0.15)$ and it is noted through the results that the production process is not under control, where exceeded the samples $(39,40)$ drawn to the limits of control.

Where there is a problem in the production line of the Pepsi, which requires processing of the imbalance, where the treatment of the imbalance in the production line, either processing the calculated sample and then return to the production line or damage the sample and correct the path of the production line, and in the company are working to destroy the sample and correct the process of adjusting the concentration of $\mathrm{CO} 2$ gas The sample was withdrawn after the correction procedure in a special register. Eleven observations were withdrawn on the production days (39, 40). The damaged sample was replaced, the correction was carried out on the production line and new samples were withdrawn after half an hour of the replacement process. The corrected data are recorded in the following table :

Table 3-2:-Product data after removing the defect of control schemes

\begin{tabular}{|c|c|c|c|c|c|c|c|c|c|c|c|}
\hline $\mathbf{x 1 0}$ & x9 & $x 8$ & $\times 7$ & $\times 6$ & $\times 5$ & $x 4$ & x3 & $\mathrm{x} 2$ & $\mathbf{x 1}$ & Date & $ت$ \\
\hline 3.57 & 3.61 & 3.59 & 3.57 & 3.61 & 3.66 & 3.67 & 3.61 & 3.59 & 3.59 & $26 / 10 / 2016$ & 1 \\
\hline 3.67 & 3.62 & 3.55 & 3.57 & 3.61 & 3.58 & 3.60 & 3.63 & 3.62 & 3.61 & $27 / 10 / 2016$ & 2 \\
\hline 3.62 & 3.52 & \begin{tabular}{|l|}
3.69 \\
\end{tabular} & 3.59 & 3.57 & 3.55 & 3.61 & 3.69 & 3.61 & 3.59 & $29 / 10 / 2016$ & 3 \\
\hline 3.60 & 3.69 & \begin{tabular}{|l|}
3.69 \\
\end{tabular} & 3.65 & 3.58 & 3.59 & 3.57 & 3.61 & 3.66 & 3.59 & $30 / 10 / 2016$ & 4 \\
\hline 3.59 & 3.57 & \begin{tabular}{|l|}
3.69 \\
\end{tabular} & 3.63 & 3.59 & 3.57 & 3.67 & 3.69 & 3.61 & 3.59 & $31 / 10 / 2016$ & 5 \\
\hline 3.62 & 3.69 & 3.57 & 3.69 & 3.65 & 3.67 & 3.62 & 3.69 & 3.61 & 3.59 & $01 / 11 / 2016$ & 6 \\
\hline 3.69 & 3.66 & \begin{tabular}{|l|}
3.61 \\
\end{tabular} & 3.57 & 3.64 & 3.59 & 3.57 & 3.61 & 3.66 & 3.59 & $02 / 11 / 2016$ & 7 \\
\hline 3.59 & 3.57 & \begin{tabular}{|l|}
3.69 \\
\end{tabular} & 3.62 & 3.54 & 3.58 & 3.57 & 3.69 & 3.61 & 3.59 & $03 / 11 / 2016$ & 8 \\
\hline 3.69 & 3.64 & 3.57 & 3.59 & 3.59 & 3.57 & 3.62 & 3.69 & 3.67 & 3.59 & $06 / 11 / 2016$ & 9 \\
\hline 3.59 & 3.57 & 3.59 & 3.69 & 3.62 & 3.59 & 3.57 & 3.69 & 3.61 & 3.59 & $07 / 11 / 2016$ & 10 \\
\hline 3.69 & 3.52 & 3.59 & 3.57 & 3.69 & 3.60 & 3.59 & 3.57 & 3.61 & 3.59 & $08 / 11 / 2016$ & 11 \\
\hline 3.68 & 3.65 & 3.57 & 3.59 & 3.69 & 3.57 & 3.58 & 3.61 & 3.54 & 3.59 & $09 / 11 / 2016$ & 12 \\
\hline 3.60 & 3.62 & 3.64 & 3.62 & 3.58 & 3.60 & 3.61 & 3.57 & 3.60 & 3.62 & $10 / 11 / 2016$ & 13 \\
\hline 3.62 & 3.68 & 3.59 & 3.57 & 3.61 & 3.62 & 3.68 & 3.69 & 3.61 & 3.61 & $14 / 11 / 2016$ & 14 \\
\hline 3.53 & 3.69 & 3.52 & 3.57 & 3.69 & 3.68 & 3.59 & 3.57 & 3.51 & 3.59 & $15 / 11 / 2016$ & 15 \\
\hline 3.57 & 3.69 & 3.59 & 3.55 & 3.62 & 3.52 & 3.57 & 3.59 & 3.64 & 3.59 & $23 / 11 / 2016$ & 16 \\
\hline 3.62 & 3.57 & 3.64 & 3.69 & 3.57 & 3.59 & 3.68 & 3.51 & 3.59 & 3.59 & $24 / 11 / 2016$ & 17 \\
\hline 3.69 & 3.52 & 3.62 & 3.57 & 3.69 & 3.59 & 3.61 & 3.57 & 3.61 & 3.59 & $27 / 11 / 2016$ & 18 \\
\hline 3.66 & 3.51 & \begin{tabular}{|l|}
3.69 \\
\end{tabular} & 3.67 & 3.57 & 3.58 & 3.69 & 3.57 & 3.61 & 3.59 & $28 / 11 / 2016$ & 19 \\
\hline 3.61 & 3.59 & 3.59 & 3.57 & 3.62 & 3.59 & 3.57 & 3.68 & 3.61 & 3.59 & $29 / 11 / 2016$ & 20 \\
\hline 3.59 & 3.55 & 3.57 & 3.61 & 3.54 & 3.68 & 3.62 & 3.69 & 3.60 & 3.59 & $30 / 11 / 2016$ & 21 \\
\hline 3.62 & 3.59 & 3.54 & 3.64 & 3.68 & 3.52 & 3.59 & 3.57 & 3.61 & 3.59 & $01 / 12 / 2016$ & 22 \\
\hline 3.61 & 3.62 & 3.69 & 3.57 & 3.68 & 3.62 & 3.60 & 3.57 & 3.69 & 3.59 & $04 / 12 / 2016$ & 23 \\
\hline 3.62 & 3.59 & 3.60 & 3.56 & 3.57 & 3.59 & 3.69 & 3.58 & 3.52 & 3.59 & $05 / 12 / 2016$ & 24 \\
\hline 3.59 & 3.57 & 3.62 & 3.52 & 3.59 & 3.57 & 3.69 & 3.61 & 3.57 & 3.59 & $06 / 12 / 2016$ & 25 \\
\hline 3.59 & 3.57 & 3.68 & 3.51 & 3.69 & 3.57 & 3.62 & 3.69 & 3.61 & 3.59 & $07 / 12 / 2016$ & 26 \\
\hline 3.65 & 3.64 & 3.61 & 3.62 & 3.59 & 3.57 & 3.60 & 3.58 & 3.61 & 3.62 & $08 / 12 / 2016$ & 27 \\
\hline 3.60 & 3.66 & 3.55 & 3.57 & 3.64 & 3.59 & 3.57 & 3.61 & 3.59 & 3.59 & $12 / 12 / 2016$ & 28 \\
\hline 3.69 & 3.52 & 3.59 & 3.67 & 3.69 & 3.62 & 3.52 & 3.69 & 3.51 & 3.59 & $13 / 12 / 2016$ & 29 \\
\hline 3.57 & 3.59 & 3.59 & 3.69 & 3.52 & 3.54 & 3.62 & 3.69 & 3.61 & 3.59 & $14 / 12 / 2016$ & 30 \\
\hline 3.58 & 3.57 & 3.69 & 3.52 & 3.58 & 3.57 & 3.60 & 3.57 & 3.61 & 3.55 & $17 / 01 / 2017$ & 31 \\
\hline 3.52 & 3.57 & 3.69 & 3.65 & 3.57 & 3.55 & 3.61 & 3.59 & 3.57 & 3.59 & $18 / 01 / 2017$ & 32 \\
\hline 3.55 & 3.65 & 3.55 & 3.64 & 3.55 & 3.60 & 3.58 & 3.65 & 3.65 & 3.55 & $19 / 01 / 2017$ & 33 \\
\hline 3.52 & 3.57 & 3.61 & 3.69 & 3.57 & 3.61 & 3.61 & 3.59 & 3.57 & 3.55 & $22 / 01 / 2017$ & 34 \\
\hline 3.69 & 3.57 & 3.64 & 3.58 & 3.59 & 3.60 & 3.61 & 3.57 & 3.66 & 3.52 & $23 / 01 / 2017$ & 35 \\
\hline 3.59 & 3.67 & 3.57 & 3.58 & 3.69 & 3.52 & 3.67 & 3.67 & 3.54 & 3.57 & $24 / 01 / 2017$ & 36 \\
\hline 3.60 & 3.61 & 3.59 & 3.64 & 3.58 & 3.62 & 3.57 & 3.69 & 3.61 & 3.59 & $26 / 01 / 2017$ & 37 \\
\hline 3.62 & 3.59 & 3.57 & 3.59 & 3.62 & 3.57 & 3.69 & 3.57 & 3.67 & 3.57 & $29 / 01 / 2017$ & 38 \\
\hline 3.50 & 3.57 & 3.55 & 3.60 & 3.67 & 3.50 & 3.61 & 3.60 & 3.69 & 3.61 & $30 / 01 / 2017$ & 39 \\
\hline 3.69 & 3.52 & 3.50 & 3.52 & 3.61 & 3.69 & 3.59 & 3.57 & 3.67 & 3.61 & $31 / 01 / 2017$ & 40 \\
\hline
\end{tabular}




\begin{tabular}{|l|l|l|l|l|l|l|l|l|l|l|l|}
3.57 & 3.60 & 3.57 & 3.58 & 3.54 & 3.64 & 3.52 & 3.51 & 3.59 & 3.59 & $01 / 02 / 2017$ & 41 \\
\hline 3.57 & 3.69 & 3.57 & 3.69 & 3.57 & 3.64 & 3.57 & 3.56 & 3.55 & 3.67 & $02 / 02 / 2017$ & 42 \\
\hline 3.57 & 3.64 & 3.69 & 3.57 & 3.61 & 3.59 & 3.57 & 3.68 & 3.61 & 3.59 & $12 / 02 / 2017$ & 43 \\
\hline 3.69 & 3.57 & 3.59 & 3.57 & 3.59 & 3.62 & 3.68 & 3.69 & 3.57 & 3.61 & $13 / 02 / 2017$ & 44 \\
\hline 3.69 & 3.54 & 3.69 & 3.62 & 3.58 & 3.62 & 3.54 & 3.69 & 3.57 & 3.59 & $14 / 02 / 2017$ & 45 \\
\hline 3.56 & 3.65 & 3.68 & 3.61 & 3.57 & 3.52 & 3.69 & 3.68 & 3.64 & 3.57 & $15 / 02 / 2017$ & 46 \\
\hline 3.52 & 3.62 & 3.69 & 3.67 & 3.67 & 3.57 & 3.55 & 3.59 & 3.64 & 3.57 & $19 / 02 / 2017$ & 47 \\
\hline 3.62 & 3.58 & 3.54 & 3.61 & 3.59 & 3.67 & 3.68 & 3.69 & 3.61 & 3.59 & $20 / 02 / 2017$ & 48 \\
\hline 3.68 & 3.59 & 3.64 & 3.69 & 3.57 & 3.69 & 3.65 & 3.57 & 3.64 & 3.59 & $21 / 02 / 2017$ & 49 \\
\hline 3.61 & 3.63 & 3.64 & 3.57 & 3.69 & 3.57 & 3.62 & 3.69 & 3.64 & 3.61 & $22 / 02 / 2017$ & 50 \\
\hline
\end{tabular}

Control plan for the average:-

Where the results of the analysis of control schemes for the Pepsi product as follows:

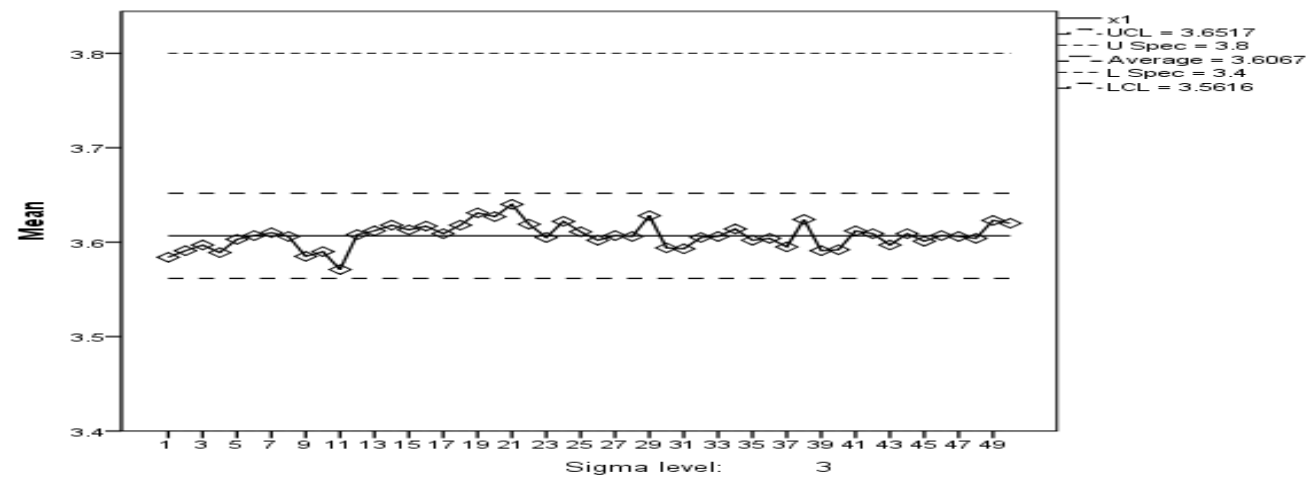

Figure 3-3:-The control scheme of the Pepsi product for the averages

The upper limit is calculated by UCL (3.8), the minimum calculated LCL (3.56), the minimum determined by the company (3.40), or the median value (3.60). The production process is within limits and there are no values beyond control, which confirms the progress of the production process on a regular basis, ie scientific within the statistical control.

\section{Control maps for the range:-}

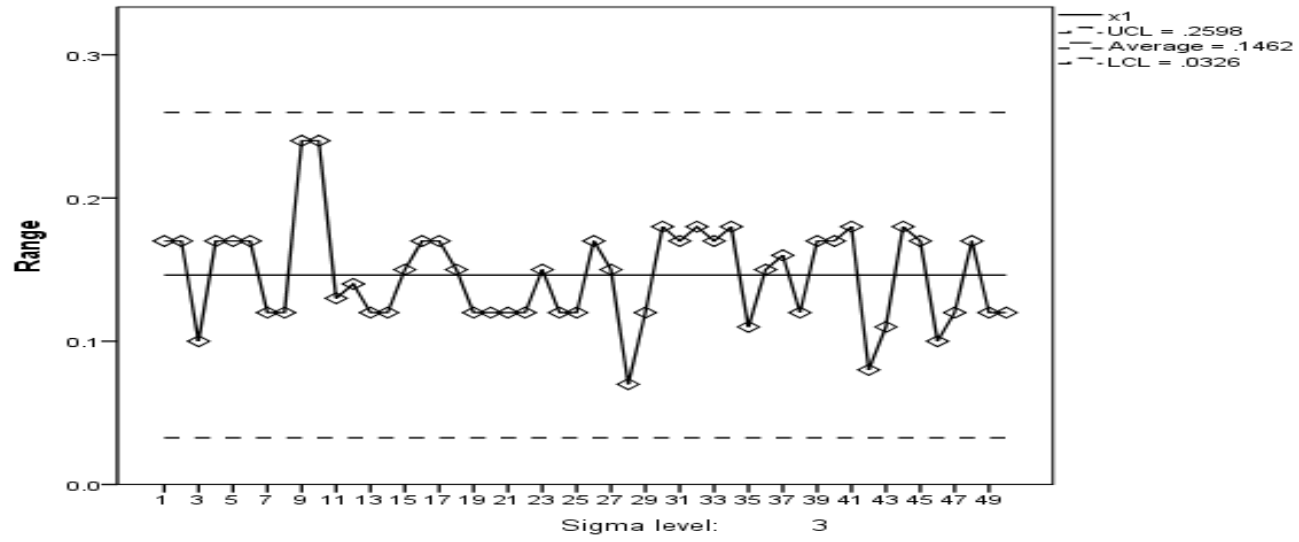

Figure 3-4:-Control scheme of the Pepsi product for the ranges

Where the results of the analysis showed that the upper limit UCL (0.26) and the minimum LCL (0.03) and the mean value CL (0.15) It is noted through the results that the production process under control and not exceed the samples drawn to the limits of control. 


\section{Production capacity index:-}

\begin{tabular}{|l|l|}
\hline Table (3-3) Indicators of production capacity of the third Pepsi product \\
\hline CPU & 1.45 \\
\hline CPL & 1.36 \\
\hline CPK & 1.36 \\
\hline CPM & 1.39 \\
\hline
\end{tabular}

Where the production is destined to the upper limit value of the index (1.40) either the production capacity of the minimum index (1.36) and was the index of the approved production limits specifications estimated value (1.36) either production Taguchi capability index was the value of (1.39), where it is compared with Table (2-1), which indicates that the quality of production of a product from the fourth level of the Pepsi level which does not achieve the highest level of the six levels of the theory of diffraction.

\section{Corrective actions:-}

From the previous analysis shown in Table 3-3, it is clear that there is a problem in the production line of the product. The problem was analyzed in the same way. The problem was solved with the competent engineers, administrative staff and problem villages. The meetings and meetings resulted in the mining and exploration of gases, gases, gases, gases, gases, gases and gases as follows:

\section{Treatment of the corrected Pepsi product:-}

After the maintenance of the buffer in the production line of the Pepsi product, the work was followed for 11 productive days, recording and processing the data using equations $(17,16)$ as shown in the following table:

Table 3-4:-Product data after corrective actions

\begin{tabular}{|c|c|c|c|c|c|c|c|c|c|c|c|}
\hline X10 & X9 & $\mathbf{X 7}$ & $\mathbf{X 7}$ & X6 & X5 & $\mathrm{X4}$ & X3 & $\mathrm{X} 2$ & X1 & التاريخ & ت \\
\hline 3.6 & 3.7 & 3.6 & 3.6 & 3.6 & 3.6 & 3.6 & 3.6 & 3.7 & 3.6 & $01 / 04 / 2017$ & 1 \\
\hline 3.6 & 3.6 & 3.6 & 3.6 & 3.6 & 3.6 & 3.6 & 3.6 & 3.6 & 3.6 & $02 / 04 / 2017$ & 2 \\
\hline 3.6 & 3.6 & 3.6 & 3.6 & 3.6 & 3.6 & 3.6 & 3.6 & 3.6 & 3.6 & $03 / 04 / 2017$ & 3 \\
\hline 3.6 & 3.6 & 3.6 & 3.6 & 3.6 & 3.6 & 3.6 & 3.6 & 3.6 & 3.6 & $04 / 04 / 2017$ & 4 \\
\hline 3.6 & 3.6 & 3.6 & 3.7 & 3.6 & 3.6 & 3.6 & 3.6 & 3.6 & 3.6 & $05 / 04 / 2017$ & 5 \\
\hline 3.6 & 3.6 & 3.6 & 3.6 & 3.5 & 3.6 & 3.6 & 3.6 & 3.6 & 3.6 & $06 / 04 / 2017$ & 6 \\
\hline 3.6 & 3.6 & 3.6 & 3.6 & 3.6 & 3.6 & 3.6 & 3.6 & 3.6 & 3.6 & $09 / 04 / 2017$ & 7 \\
\hline 3.6 & 3.6 & 3.6 & 3.6 & 3.6 & 3.6 & 3.6 & 3.6 & 3.6 & 3.6 & $10 / 04 / 2017$ & 8 \\
\hline 3.6 & 3.7 & 3.6 & 3.6 & 3.6 & 3.6 & 3.6 & 3.6 & 3.7 & 3.6 & $11 / 04 / 2017$ & 9 \\
\hline 3.6 & 3.6 & 3.6 & 3.7 & 3.6 & 3.6 & 3.6 & 3.6 & 3.6 & 3.6 & $12 / 04 / 2017$ & 10 \\
\hline 3.6 & 3.6 & 3.6 & 3.6 & 3.6 & 3.6 & 3.6 & 3.6 & 3.6 & 3.6 & $13 / 04 / 2017$ & 11 \\
\hline
\end{tabular}

Results of the modified Pepsi product data:-

Equations $(5,4,3)$ and $(9,8,7)$ respectively were applied to calculate the control schemes for the average and duration as shown below:

- Control plan for the average: 


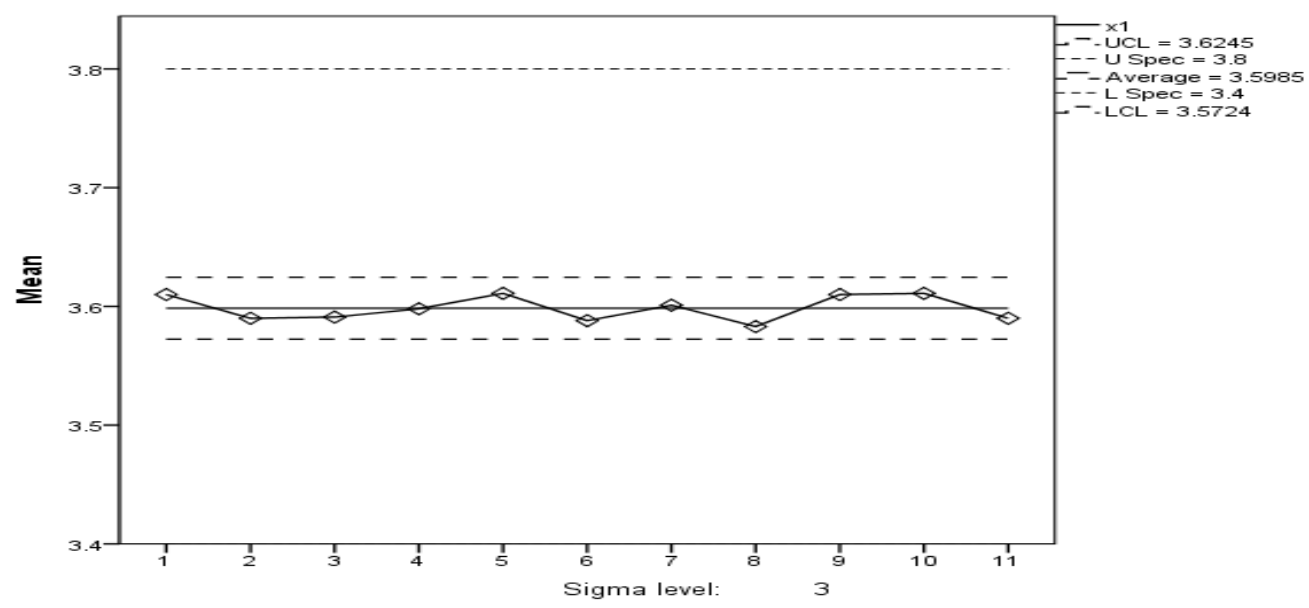

Figure 3-5:-Control scheme using the average of the modified product data

Where the analysis shows the calculated upper limit of UCL at 3.63, the maximum limit determined by UCL at 3.8 and the minimum calculated LCL at 3.57 and the minimum determined by the company at 3.40 or the median value of 3.60. The production process is within limits and there are no values beyond control, which confirms the process of production in a systematic manner which is scientifically disciplined.

\section{Control plan for the range:-}

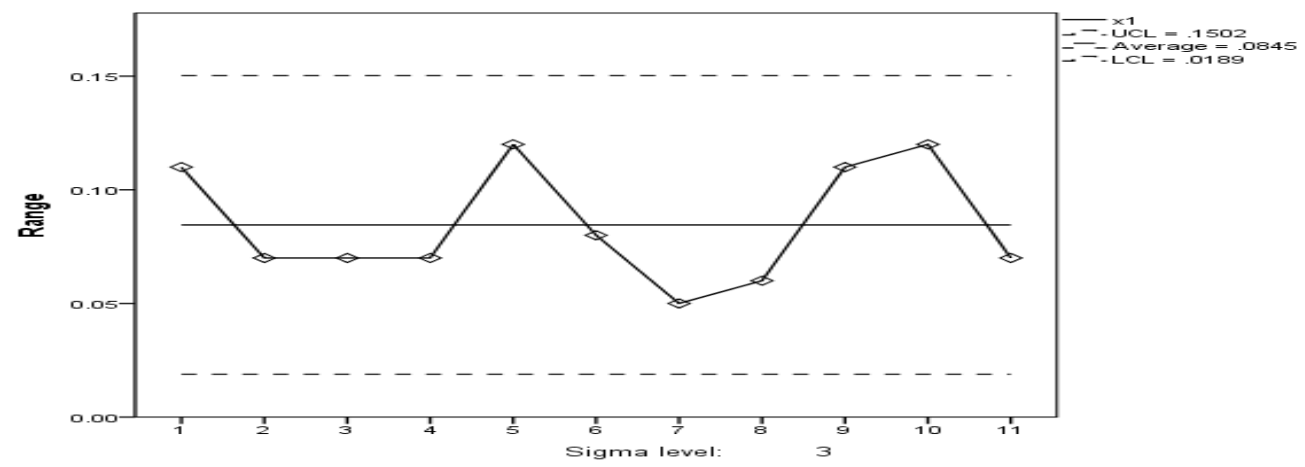

Figure (3-14) Control scheme using the ranges of the modified product data

Where the results of the analysis showed that the upper limit UCL (0.15) and the minimum LCL (0.02) and the mean value CL (0.09) and notes through the results that the production process under control and not exceed the samples drawn to the limits of control.

Second estimated production indicators:-

\begin{tabular}{|l|l|}
\hline Table (3-5) Production Capability Indicators for the Third Pepsi Product \\
\hline CPU & 2.41 \\
\hline CPL & 2.45 \\
\hline CPK & 2.41 \\
\hline CPM & 2.42 \\
\hline
\end{tabular}

Where the production is destined to the upper limit value of the index (2.41) either the production capacity of the minimum index (2.45) and was the index of the approved production limits specifications estimated value (2.41) either production Taguchi capability index was the value of (2.42), where it is compared with Table (2-1) in the second quarter, which indicates that the quality of the level of production of a product from the sixth average Pepsi level which achieves a high level of the six levels of diffraction theory, a good indicator of the company. 


\section{Analysis of results:-}

After the repeated readings of the company's data of 500 samples and the withdrawal of the Pepsi product in addition to the third Pepsi product data corrected using the intermediary were processed. The results of the Pepsi product analysis showed that the product production process is statistically controlled and controlled within control limits after treatment of the defect causing the process not to be statistically controlled, While the results of the indicators of production of the product showed that the figure is close to (1.5), which corresponds to the level of the fourth level of the theory of diffraction of the six, an indication of the existence of defect in the production line, which requires the creation of imbalances and work to repair it temporarily for the purpose of study.

After the maintenance and recording of the data for 11 productive days, the results of the analysis showed that the production process is disciplined and the production capacity was equal to (2.45) indicating that the product quality level is the sixth level of the theory.

\section{Conclusions:-}

Through the results that emerged from the analysis of the company's data, several conclusions were reached:

1. The company under study does not apply the methodology of six sigma theory, but the company works in 3D system for testing samples and estimating the quality of its products, which are carried out by the Canadian laboratories, where this system consists of three parts of the examination based on the physical examination and examination of components and examination taste by specialists, The quality level is assessed at $100 \%$ to achieve customer satisfaction.

2. There are three limits of control adopted by the company limits of control prescribed by the parent company and the limits of control prescribed by the standardization and quality control in Iraq and limits limits set by Baghdad Company, which generates repeated readings of the withdrawn observations, which requires processing by using the mediator.

3. The results of the Pepsi product showed that the production process was not statistically controlled. After processing the defect and withdrawing new samples, the production process became statistically controlled. The production capacity indicators were (1.4) indicating that the quality of the product is in the fourth level of the six. There is a defect in the production line.

4. The results of the analysis of the Pepsi product after the diagnosis of the defect on the production line were proved by replacing the causative part (the idle part). The product production process was within the statistical control. The results of the production capacity indices were (2.45) The fourth level to the sixth level of the theory of six sigma .

5. The application of the company approach to the theory of six sigma because of the effectiveness of this approach in detecting defects in any part of the parts of production lines and achieve customer satisfaction.

6. The company to replace the idle part of the pump machine because it is the reservoir of imbalance in the production line Pepsi product, which leads to the product of the level of the fourth level of sigma .

\section{Sources:-}

1. Al-Qazzaz, Ismail Ibrahim, Al-Hadithi, Rami Hekmat, and Corel, Adel Abdul Malik, (2009). six sigma and other modern methods in TQM. Amman: Dar Al Masirah for Publishing and Distribution.

2. Ismail Mayser and Jubouri, Ibrahim Ahmed. (2009). Statistical concept of Six Sigma technology and its relationship to process improvement activities. Development of Rafidain, 19.

3. Adaily, Fadi Hassan Hussein. (2014). Six Sigma approach and its role in reducing costs and enhancing competitiveness. University of Zarqa, 102.

4. The world, Fathi Ahmed. (2010). Total Quality Management System and International Standards Scientific and Applied Study. Amman: Dar Alawazri Scientific Publishing and Distribution.

5. Al-Assas, Basil. (2014). Application of the methodology of the orthodontic Sikma in the Syrian pharmaceutical industry / case study of the company of the pharmaceutical industries. The Virtual University of Syria, 166.

6. Massoudi, Haidar Ali. (2010). Managing quality costs is a strategy. Amman: Dar Alawazri Scientific Publishing and Distribution.

7. Al-Nuaimi, Mohammed Abdel-Aal, Sweis, Ratib Jalil, Sweis, Ghaleb Jalil. (2009). Contemporary Quality Management Introduction to Total Quality Management for Production, Operations and Service. Amman: Dar Alawazri Scientific Publishing and Distribution.

8. The narrator, Khasha Mohammed. (1989). Introduction to Statistics. Mosul: University of Mosul. 
9. Dawood, Ghassan Abdul Karim, Karim, Azzam Abdul Wahab. (2016). Application of Lean Six Sigma tools in the two stages of definition and measurement in the development of new product / case study in the General Company for Electrical Industries. Journal of Economic and Administrative Sciences, 22.

10. live, Mohammed Ahmed. (2007). Quality Control Basic technologies and their applications in the fields of production and service. Riyadh: Dar Al-Ashab for publishing and distribution.

11. Anil, K., M., R. J., \& A., M. J. (2014). USING SIX SIGMA FOR PERFORMANCE IMPROVEMENT IN BUSINESS CURRICULUM:A CASE STUDY. Performance Improvement, 19.

12. Athanasios, B., \& Loucopoulos, P. (2017). Six Sigma DMAIC Enhanced with Capability Modelling. IEEE, 8.

13. Derian, R. M. (2013). SYSTEMS THINKING AND SIX SIGMA: EXPLORING AN INTEGRATED MODEL FOR QUALITY MANAGEMENT. Pepperdine University, 377.

14. Kai, Y., \& EL-Haik, B. (2003). Design for Six Sigma A Roadmap for Product Development. Inc: McGraw-Hill Companies.

15. Konert, T., \& Schmidt, A. (2010). Design for Six Sigma. München: HANSER.

16. Mathran, i. M. (2017). A Six Sigma Approach Towards Improving Quality Management in Manufacturing of Nutritional Products. IEEE, 5.

17. Montgomery, D. C. (2009). Introduction to Statistical Quality Control. Inc: John Wiley \& Sons.

18. Park, S. H. (2003). Six Sigma for Quality and Productivity Promotion. jaban: Asian Productivity Organization.

19. Yanhui, H., David, D., \& J., J. K. (2016). Applying Linear Programming Method in Six Sigma Approach to Developa TruckPlanning Tool - A Case Study. IOSR Journal of Business and Management, 6. 